\title{
DIMENSI METRIK PADA GRAF TURAN
}

\author{
Ninik Mutianingsih \\ Universitas PGRI Adi Buana Surabaya \\ email : ninikmutia27@gmail.com
}

\begin{abstract}
Abstrak
Himpunan $W$ adalah resolving set (himpunan pembeda) dari $G$ jika setiap simpul di $G$ memiliki representasi tunggal pada $W$ yang ditentukan oleh jarak dari simpul dari $G$ terhadap simpul di $W$. Dimensi metrik dari $G$ adalah kardinalitas minimum dari resolving set pada $G$. Pada paper ini akan dijelaskan tentang dimensi metrik pada graf Turan, yaitu graf multipartisi komplit yang dinotasikan dengan $T_{k, n}$ dengan $k$ adalah banyaknya seluruh simpul dari graf dan $n$ adalah banyaknya partisi. Dimensi metrik dari graf $T_{k, n}$ dengan $k=n^{2}$ adalah $\operatorname{dim}\left(T_{k, n}\right)=k-n$. Sedangkan untuk graf Turan yang tidak komplit $T_{k, n}$ yang memiliki order $k-1$ dengan menjaga keterhubungan antara setiap simpul pada semua partisi memiliki dimensi metrik yaitu $\operatorname{dim}\left(\left|T_{k, n}\right|=k-1\right)=1$.
\end{abstract}

Kata Kunci : dimensi metrik, graf Turan, resolving set

\section{A. Pendahuluan}

Teori graf aljabar adalah cabang dari matematika yang mempelajari graf dengan menggunakan sifat-sifat aljabar [1]. Graf satu dengan yang lainnya mempunyai karakter masing-masing sehingga berbeda antara satu sama lain. Salah satu karakter tersebut adalah dimensi metrik.

Dimensi metrik pertama kali dikenalkan oleh Harary dan Melter [2]. Dimensi metriks adalah resolving set dari $G$ dengan kardinalitas minimum. $W \subseteq G$ dikatakan sebagai resolving set dari $G$ jika $G$ memiliki representasi tunggal pada $W$ yaitu ditentukan oleh jarak dari simpul-simpul di $G$ terhadap simpul-simpul di $W$.

Banyak penelitian yang sudah dilakukan untuk mengetahui dimensi metrik dari suatu graf. Penelitian tersebut antara lain dilakukan oleh Saputro dkk dengan judul The Metric Dimension of a Complete $n$ Partite Graphs and Its Products [3] yang meneliti graf $n$-partisi komplit dengan operasi cartesian dan corona serta meneliti graf lintasan dan sikel. Ada juga Chartrand dkk dengan Resolvability in Graphs and The Metric Dimension of a Graph [4] pada tahun
2000 yang menghasilkan $\operatorname{dim}\left(P_{n}\right)$, $\operatorname{dim}\left(K_{n}\right)$, dan graf-graf yang mempunyai dimensi metriks $n-2$, juga oleh Jannesari dkk [9]. Selain itu ada juga penelitian dimensi metrik yang dikenakan pada tree dan graf bintang [2,6,7] yang diteliti oleh Khuller dkk, dan juga oleh Harary, graf Cayley [10] yang diteliti oleh Fehr dkk, pada unicyclic graphs [5] oleh Rodriguez dkk, pada graf bipartisi komplit [8], graf yang memiliki pendan [11] oleh Iswadi dkk, dan pada graf lintasan [12] oleh Fajjria. Pada paper ini akan ditentukan dimensi metrik dari graf Turan yang dinotasikan dengan $T_{k, n}$, yaitu graf multipartisi komplit yang mempunyai simpul total $k$ simpul dan di setiap partisinya memiliki simpul sebanyak $\frac{k}{n}$. Namun pada paper ini penulis membatasi graf Turan yang akan dibahas, yaitu graf Turan yang mempunyai simpul total sebanyak $k$ dengan partisi sebanyak $n$ namun $\mathrm{k}$ terbagi habis dengan $n$ sehingga $k=n x$. Dengan kata lain graf $T_{k, n}$ adalah graf multipartisi komplit dengan di setiap partisinya mempunyai jumlah simpul yang sama sebanyak $x$ simpul. 


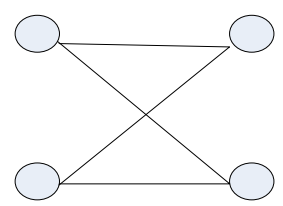

(a)

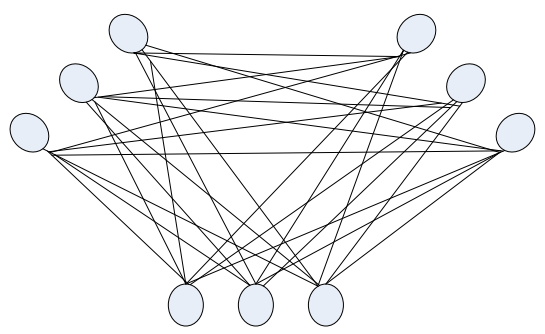

(b)

Gambar 1: (a) Graf bipartisi komplit atau graf $T_{4,2}$

(b) Graf tripartisi komplit atau graf $T_{9,3}$

\section{B. Resolving Set dan Dimensi Metrik dari Suatu Graf}

Misal $G$ adalah graf, $V_{G}$ adalah himpunan simpul pada $G$ dan $E_{G}$ adalah himpunan sisi pada $G$. Jarak antara simpul $u, v \in G$ dinotasikan dengan $d(u, v)$ yaitu lintasan terpendek yang menghubungkan simpul $u$ dan $v$ di $G$. Misal $W \subseteq V_{G}$ dengan $W=\left\{w_{1}, w_{2}, w_{3}, \ldots, w_{n}\right\}, \quad r(v \mid W)=$ $\left(d\left(v, w_{1}\right), d\left(v, w_{2}\right), d\left(v, w_{3}\right), \ldots, d\left(v, w_{n}\right)\right)$ adalah representasi $v$ relatif terhadap $W$ dengan $v \in G . W$ dikatakan sebagai resolving set (himpunan pembeda) dari $G$ jika representasi simpul di $G$ berbeda antara simpul satu dengan simpul yang lainnya. Sedangkan dimensi metrik dari suatu graf yang dinotasikan dengan $\operatorname{dim}(G)$ adalah kardinalitas terkecil dari resolving set (himpunan pembeda) $W$ [4].

Sebagai contoh, [4] misal $G$ adalah graf yang diberikan pada gambar 2. Diberikan $W_{1}=\left\{v_{1}, v_{3}\right\}$ bukan resolving set dari $G$ karena representasi $W_{1}$ pada $G$ menghasilkan representasi yang sama, yaitu $r\left(v_{2} \mid W_{1}\right)=(1,1)=r\left(v_{4} \mid W_{1}\right)$. Sedangkan untuk $W_{2}=\left\{v_{1}, v_{2}, v_{3}\right\}$ adalah resolving set dari $G$ karena representasi dari semua simpul di $G$ berbeda, yaitu:

$$
\begin{aligned}
& r\left(v_{1} \mid W_{2}\right)=(0,1,1) \\
& r\left(v_{2} \mid W_{2}\right)=(1,0,1) \\
& r\left(v_{3} \mid W_{2}\right)=(1,1,0) \\
& r\left(v_{4} \mid W_{2}\right)=(1,2,1) \\
& r\left(v_{5} \mid W_{2}\right)=(2,1,1)
\end{aligned}
$$

Berikut adalah gambar graf $G$ :

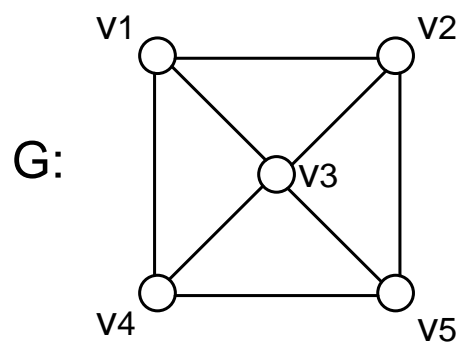

Gambar 2.

Meskipun demikian, $W_{2}$ bukan dimensi metrik dari $G$ karena $W_{3}=\left\{v_{1}, v_{2}\right\}$ juga resolving set dari $G$.

$$
\begin{aligned}
& r\left(v_{1} \mid W_{3}\right)=(0,1) \\
& r\left(v_{2} \mid W_{3}\right)=(1,0) \\
& r\left(v_{3} \mid W_{3}\right)=(1,1) \\
& r\left(v_{4} \mid W_{3}\right)=(1,2) \\
& r\left(v_{5} \mid W_{3}\right)=(2,1)
\end{aligned}
$$

Dari representasi di atas dapat diketahui bahwa representasi dari semua simpul oleh $W_{3}$ berbeda. Maka dapat dikatakan bahwa $W_{3}$ adalah resolving set dari $G$ dengan kardinalitas minimum yaitu 2 . Sehingga dimensi metrik dari $G$ adalah $\operatorname{dim}(G)=$ $\left|W_{3}\right|=2$.

\section{Dimensi Metrik dari Graf Turan}

Pada paper ini akan ditunjukkan dimensi metrik dari graf Turan yang dinotasikan $T_{k, n}$, namun penulis membatasi graf Turan pada graf Turan yang mempunyai simpul total sebanyak $k$ dengan partisi sebanyak $n$ namun $k=n^{2}$.

Definisi 1. Graf Turan adalah graf multipartisi komplit yang mempunyai simpul total $k$ simpul dan di setiap partisinya memiliki simpul sebanyak $\frac{k}{n}$ dengan $n$ adalah jumlah partisinya [13].

Lemma 1. $G$ adalah graf $n$-partisi komplit dengan $n \geq 2$ dan $W$ adalah resolving set dari $G$. Misalkan $W^{\prime}=G-W$ maka $W^{\prime}$ memuat paling banyak satu simpul dari setiap partisi. $W^{\prime}$ juga memuat paling 
banyak satu simpul dari semua partisi singleton [3].

Lemma 2. $G$ adalah graf $n$-partisi komplit dengan $n \geq 2$. Misalkan $W$ adalah resolving set dari $G$ maka paling banyak satu simpul di $G$ yang tidak dimuat oleh $W$ [3].

Teorema 1. Misalkan $T_{k, n}$ adalah graf Turan dengan $k=n^{2}$ dan $n \geq 2$, maka

$$
\operatorname{dim}(G)=k-n
$$

\section{Bukti.}

Untuk batas bawah dari $T_{k, n}$, dengan menggunakan lemma 2. Misalkan $W$ adalah resolving set dari $G$. Andaikan terdapat dua simpul $v_{1}, v_{2} \in V_{G}$ yang terletak pada satu partisi dengan $v_{1}, v_{2} \notin W$. karena $v_{1}$ dan $v_{2}$ terhubung dengan simpul yang sama maka $r\left(v_{1} \mid W\right)=r\left(v_{2} \mid W\right)$. Hal ini tidak mungkin karena akan mengakibatkan representasi yang tidak berbeda sehingga $W$ bukan resolving set dari $G$. Pernyataan ini kontradiksi dengan pernyataan bahwa $W$ adalah resolving set dari $G$, maka haruslah $v_{1}$ dan $v_{2}$ berada pada partisi yang berbeda. Sehingga jika graf $T_{k, n}$ terpartisi menjadi $n$ partisi maka terdapat $n$ simpul dari partisi yang berbeda, sehingga jika $\left|V_{G}\right|=k$ maka $\operatorname{dim}(G) \geq k-n$.

Untuk batas atas misalkan $W^{\prime}=$ $\left\{v^{1}, v^{2}, v^{3}, \ldots, v^{n}\right\}$ dengan $\left|W^{\prime}\right|=n$ adalah satu simpul yang diambil dari partisi yang berbeda, dan $W$ dapat dikatakan resolving set dari $G$, sehingga $W=G-W^{\prime}$. Misal $v_{1}, v_{2} \in V_{G}$ berlaku $r\left(v_{1} \mid W\right)=r\left(v_{2} \mid W\right)$. Jika $v_{1}$ atau $v_{2}$ di resolving set maka $v_{1}=$ $v_{2}$. Namun jika $v_{1}, v_{2} \in W^{\prime}$ maka $v_{1}$ dan $v_{2}$ berada pada partisi yang berbeda sehingga akan memiliki representasi yang berbeda karena $d\left(v_{1}, W_{v_{2}}\right)=d\left(v_{2}, W_{v_{1}}\right)=1$ dan $d\left(v_{1}, W_{v_{1}}\right)=d\left(v_{2}, W_{v_{2}}\right)=2$ dengan $W_{v_{1}}$ adalah partisi yang memuat $v_{1}$ dan $W_{v_{2}}$ adalah partisi yang memuat $v_{2}$. Misal $\left|V_{G}\right|=k$ sehingga $\operatorname{dim}(G) \leq k-n$. Karena batas bawah dari $\operatorname{dim}(G) \geq k-n$ dan batas atas dari $\operatorname{dim}(G) \leq k-n$, maka $\operatorname{dim}(G)=$ $k-n$ dengan $G=T_{k, n}$.

Remarks 1. Teorema 1 diperkuat oleh hasil sebelumnya, yaitu:

$$
\begin{aligned}
& \operatorname{dim}(G) \\
& = \begin{cases}\left|V_{G}\right|-1-(n-m), & \text { for } m>0 \\
\left|V_{G}\right|-n, & \text { for } m=0\end{cases}
\end{aligned}
$$

Teorema 2. Graf Turan yang tidak komplit dan mempunyai order $\left|T_{k, n}\right|=k-1$ dengan menjaga keterhubungan antara setiap simpul pada semua partisi memiliki dimensi metrik yaitu $\operatorname{dim}\left(\left|T_{k, n}\right|=k-\right.$ 1) $=1$.

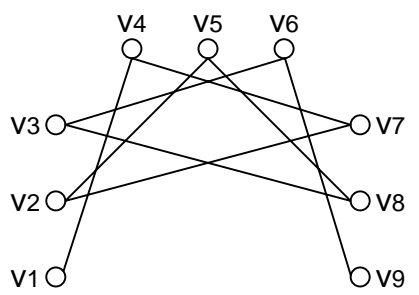

Gambar 3. Contoh graf Turan dengan order

Bukti.

$$
\left|T_{k, n}\right|=k-1
$$

Misalkan $u$ dan $v$ adalah simpul-simpul pada $T_{k, n}$ yang mempunyai order $k-1$ dan jarak antara $u$ dan $v$ adalah $d(u, v)=d$ dengan $0 \leq d \leq k-2$. Misal $u_{i}=v_{i}$ dengan $0 \leq i \leq k-1$, untuk $u_{0} \in W$ dan $W=V_{G}-\left(u_{i}-u_{0}\right)$. Karena $d\left(u_{0}, u_{i}\right)=i$ untuk $1 \leq i \leq k-1$, maka $W=\left\{u_{0}\right\}$ adalah resolving set dengan minimum kardinalitas yaitu $k-1-d$. Karena untuk menghasilkan jarak yang terkecil, maka digunakan $d$ maksimal yaitu $k-2$. Sehingga untuk kardinalitas minimum dari $W$ adalah $k-1-d=k-1-(k-2)=$ $k-1-k+2=1$. Sehingga untuk graf $T_{k, n}$ dengan order $k-1$ mempunyai dimensi metrik yaitu $\operatorname{dim}\left(\left|T_{k, n}\right|=k-\right.$ 1) $=1$.

Jika graf Turan yang memiliki order $k-1$ dijabarkan, graf tersebut membentuk graf lintasan dengan simpul sebanyak $k$ dan order sebanyak $k-1$. Sehingga dapat dikatakan bahwa dimensi metrik dari graf Turan yang memiliki order $k-1$ sama dengan dimensi metrik dari graf lintasan $P_{k}$, yaitu $\operatorname{dim}\left(\left|T_{k, n}\right|=k-1\right)=\operatorname{dim}\left(P_{k}\right)=1$.

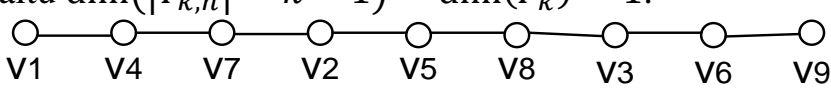

Gambar 4. Penjabaran dari graf Turan $T_{9,3}$ (gambar 3) yang memiliki order 8 
Remark 2. Teorema 2 diperkuat oleh hasil sebelumnya, yaitu:

a. Jika $G$ adalah sebuah graf terhubung dengan order $n \geq 2$ dan diamater $d$, maka $f(n, d) \leq \operatorname{dim}(G) \leq n-d$

b. Sebuah graf terhubung $G$ dengan order $n$ mempunyai dimensi metrik 1 jika dan hanya jika $G=P_{n}$.

Corollary 2. Graf Turan yang tidak komplit dan mempunyai order $\left|T_{k, n}\right|=k$ dan juga $\delta\left(T_{k, n}\right)=2$ memiliki dimensi metrik yaitu $\operatorname{dim}\left(T_{k, n}\right)=2$.

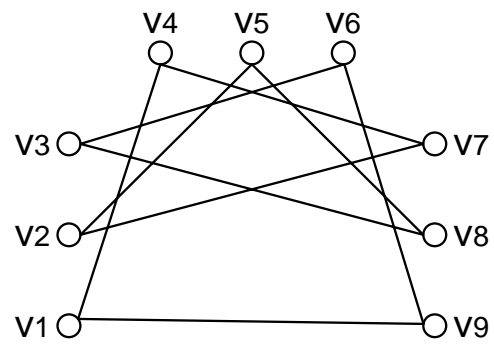

Gambar 5. Contoh graf Turan dengan order

$$
\left|T_{k, n}\right|=k \text { dan } \delta\left(T_{k, n}\right)=2
$$

\section{Daftar Pustaka}

[1] F.K.N. Sari, Spektrum Adjacency, Spektrum Laplace, dan Spektrum Signless-Laplace Graf Multipartisi Komplit $K_{\alpha_{1}, \alpha_{2}, \alpha_{3}, \ldots, \alpha_{n}}$, UIN Malang, 2013.

[2] F. Harary, and R.A. Melter, On The Metric Dimension Of A Graph, Ars combin. 2 1076, 191-195.

[3] S.W. Saputro, E.T. Baskoro, A.N.M. Salman, dan D. Suprijanto, the Metric Dimension Of A Complete n-Partite Graphs And Its Products, ITB.

[4] G. Chatrand, L. Eroh., M. A. Johnson, dan O. R Oellermann, Resolvability in Graphs and The Metric Dimension of a Graph, Discrete Appl. Math., 105 (2000), 99-113.

[5] J.A. Rodriguez, I.G. Yero, dan H. Fernau, On The Partition Dimension Of Unicyclic Graphs, preprint, 2013.

[6] S. Khuller, B. Raghavachari, dan A. Rosenveld, Landmarks in Graphs, Discrete Appl. Math., 70 (1996), 217 229.
[7] J. Caceres, D. Garijo, M.L. Puertas, dan c. Seara, On The Determining Number and The Metric Dimension Of Graphs, Discrete Appl. Math., 17 (2010).

[8] M. Baca, E.T. Baskoro, A.N.M. Salman, S.W Saputro, dan D. Suprijanto, The Metric Dimension of Regular Bipartite Graphs, Bull. Math. Soc. Math. Roumanie Tome, No. 1 (2011) 15-28.

[9] M. Jannesari, dan B. Omoomi, The Metric Dimension of The Composition Product of Graphs, Isfahan University.

[10] M. Fehr, S. Gosselin, dan O.R. Oellermann, The Metric Dimension Of Cayley Digraphs, Discrete Math. 306 (2006) 31-41.

[11] I. Iswadi, E.T. Baskoro, R. Simanjuntak, dan A.N.M. Salman, The Metric Dimension Of Graphs with Pendant Edges, J. Combin. Math. Combin. Comput., 65 (2008) 139-145.

[12] I.M.D. Fajjria, Dimensi Metrik Graf Lintasan Tak Hingga, UIN Malang, 2010.

[13] N. Faizah, Spectrum Adjacency, Spectrum Detour dan Spectrum Laplace pada Graf Turan, UIN Malang, 2012. 